Short communication

\title{
Herbs in association with drugs: Enhancement of the aminoglycoside- antibiotic activity by Pityrogramma calomelanos (L.) Link
}

\author{
Teógenes M. Souza ${ }^{a}$, Maria F.B. Morais-Braga ${ }^{a}$, José G.M. Costa ${ }^{b}$, Antônio A.F. Saraiva ${ }^{c}$, \\ Micheline A. Lima ${ }^{\mathrm{d}}$, Henrique D.M. Coutinho ${ }^{\mathrm{a}, *}$ \\ a Laboratory of Microbiology and Molecular Biology, Department of Biological Chemistry, University of the Region of Cariri, CE/Crato, CE, Brazil \\ ${ }^{\mathrm{b}}$ Laboratory of Natural Products Research, Department of Biological Chemistry, University of the Region of Cariri, CE/Crato, Brazil \\ ${ }^{\mathrm{c}}$ Laboratory of Paleontology, Department of Biological Sciences, University of the Region of Cariri, CE/Crato, Brazil \\ d Laboratory of Biochemistry and Cellular Biology, Department of Ecology and Environment, Federal University of Paraiba, PB/Rio Tinto, Brazil
}

\section{A R T I C L E I N F O}

\section{Article history:}

Received 25 August 2013

Accepted 19 October 2013

Available online xxx

\section{Keywords:}

Antimicrobial activity

Ethyl acetate fraction

Hexane fraction

Pityrogramma calomelanos

Modifying antibiotic activity

\begin{abstract}
A B S T R A C T
Aims: In this work, the ethyl acetate and hexane fractions of Pityrogramma calomelanos (L.) were evaluated to antibacterial and antifungal activity against strains of Escherichia coli, Pseudomonas aeruginosa, Staphylococcus aureus, Candida albicans, Candida krusei and Candida tropicalis.

Methods: The study was performed aiming to assess the antimicrobial effect with the method of dilution in HIA. The hexane and ethyl acetate fractions were named HFPC and EAFPC, respectively.

Results: Both fractions of specie P. calomelanos displayed good activity against $S$. aureus when associated with gentamicin. When associated with the antifungal, the fractions did not exhibit relevant activity against species of Candida.

Conclusions: These results indicate that this specie can be used as a possible source of natural products of antibacterial interest, mainly when combined with aminoglycosides.
\end{abstract}

Copyright $\odot$ 2013, InPharm Association, Published by Reed Elsevier India Pvt. Ltd. All rights reserved.

\section{Introduction}

Nosocomial infections are a serious problem of public health around the globe, causing significant increases in morbidity, mortality and hospital costs. Among the main pathogens involved in these infections stands Staphylococcus aureus. The clinical manifestations of $S$. aureus can be cutaneous or systemic. The cutaneous symptoms include folliculitis, boils, carbuncles and the skin scalded Staphylococci syndrome. S. aureus is frequently isolated in postsurgical wounds, and therefore is a serious problem due causing systemic infections. When cause bacteremia, that bacteria can produce endocarditis, osteomyelitis, piocarditis and meningitis. ${ }^{1}$

In health field, other bacterium of clinical importance is Escherichia coli. In humans, this microorganism has been identified as the primary cause of urinary tract infections, neonatal meningitis, nosocomial septicemia and enteritis. Pseudomonas aeruginosa also is found among the bacteria of greater clinical relevance, being the cause of infections in immunocompromised patients, as occurs

\footnotetext{
* Corresponding author. Departamento de Química Biológica, Universidade Regional do Cariri - URCA, Rua Cel. Antonio Luis 1161, Pimenta, Crato-CE 63105000, Brazil. Tel.: +55 (88) 31021212; fax: +55 (88) 31021291.

E-mail addresses: hmcoutinho@urca.br, hdouglas@zipmail.com.br (H.D.M. Coutinho).
}

in cystic fibrosis. Furthermore, this bacterium presents high rate of spontaneous mutations, resulting in progressive enhancement in the antibiotic resistance, raising difficulties in the anti-infective therapy. ${ }^{2}$

Another growing problem is the increase of bacterial resistance to antibiotics. The resistances at two or more antimicrobial classes have been reported frequently in human and veterinary medicine, limiting the available therapeutic options. The increasing of the antibiotic resistance enhances the morbidity, mortality and the treatment costs. ${ }^{3}$

In the traditional medicine, the plants are used together with the conventional medicines. In this association, the medicinal plants or their sub-products can act inhibiting or increasing the therapeutic effect of conventional drugs. The plants with therapeutics properties used in the traditional medicine are an important source of news biologically active compounds. The use of extracts with antimicrobial agents presents a low possibility of resistance development by the microorganisms because these natural products are complex chemical mixtures. Modifier of antibiotic activity is a term used to name substances that modulate or even reverse bacterial resistance to specific antibiotics, such as the case of several natural products of plant origin (extracts and phytoconstituents) that change the microbial susceptibility to antibiotics for inhibition of efflux of pumps. ${ }^{4}$ 
Table 1

Origin of bacterial strains and profile of resistance at antibiotics.

\begin{tabular}{|c|c|c|}
\hline Bacteria & Source & Resistance profile \\
\hline Escherichia coli 27 & Surgical wound & $\begin{array}{l}\text { Ast, Ax, Ami, Amox, Ca, Cfc, Cf, Caz, } \\
\text { Cip, Clo, Im, Can, Szt, Tet, Tob }\end{array}$ \\
\hline $\begin{array}{l}\text { Staphylococcus } \\
\text { aureus } 358\end{array}$ & Surgical wound & $\begin{array}{l}\text { Oxa, Gen, Tob, Ami, Can, Neo, Para, } \\
\text { But, Sis, Net }\end{array}$ \\
\hline $\begin{array}{l}\text { Pseudomonas } \\
\text { aeruginosa } 03\end{array}$ & Uroculture & Cpm, Ctz, Imi, Cip, Ptz, Lev, Mer, Ami \\
\hline
\end{tabular}

Ast - Aztreonan; Ax - Amoxacillin; Amp - Ampicillin; Ami - Amicillin; Amox Amoxillin, Ca - Cefadroxil; Cfc - cefaclor; Cf - Cephalothin; Caz - Ceftazinidima; Cip - Ciprofloxacin; Clo - Chloraphenicol; Imi - Imipenem; Can - Kanamycin; Szt - Sulphametrim; Tet - Tetracycline; Tob - Tobramycin; Oxa - Oxacillin; Gen Gentamicin; Neo - Neomycin; Para - Paromomycin; But - Butirosin; Sis - Sisomicin; Net - Netilmicin; Com - Cfepime; Ctz - Ceftazidime; Ptz - Piperacillintazobactam; Lev - Levofloxacin; Mer - Merpenem.

The family Pteridaceae presents a high morphological diversity, several species occurring in the tropical and arid regions. About 50 genus and 950 species are arranged in this family. Pityrogramma is a genus with 17 species, occurring mainly in the Tropical America. The species Pityrogramma calomelanos (L.) Link is popularly known as "feto-branco", "avenca-branca" or "avenca-preta" and is used as ornamental and medicinal plant in the traditional medicine. ${ }^{5}$

The objective of the present work was to identify the main classes of chemical compounds and to evaluate the inflection of antimicrobial activity of ethyl acetate and hexane fractions from the leaves of $P$. calomelanos.

\section{Material and methods}

\subsection{Bacterial strains}

The bacterial strains used were: E. coli (EC-ATCC10536 and EC27), S. aureus (SA-ATCC25923 and SA358) and P. aeruginosa (ATCC15442 e PSU 03) with profile of resistance showed in Table 1. All the strains were kept in heart infusion Agar slants (HIA; Difco) and before the assays, the cells were cultured during $24 \mathrm{~h}$ at $37^{\circ} \mathrm{C}$ in brain heart infusion (BHI, Difco). All the strains were obtained from collection microorganisms of mycology laboratory - UFPB.

\subsection{Fungal strains}

The fungal strains used were: Candida albicans ATCC 40227, Candida krusei ATCC 6538 and Candida tropicalis ATCC 13803. All the strains were kept in heart infusion Agar slants (HIA; Difco) and before of the assays, the cells were cultured during $24 \mathrm{~h}-37^{\circ} \mathrm{C}$ in brain heart infusion (BHI, Difco). The strains were obtained from the Microorganisms Collection of Mycology Laboratory - UFPB.

\subsection{Plant materia}

Leaves of $P$. calomelanos were collected in the rainy season (September, 2009) in the county of Crato, Ceará State, Brazil. The plant material was identified by Dr. Antonio Álamo Feitosa Saraiva from University of the Region of Cariri, Crato, CE, Brazil, and voucher specimen have been deposited with the identification number 5570 at the Herbarium "Dárdano de Andrade Lima" University of the Region of Cariri, Crato, CE, Brazil.

\subsection{Drugs}

Solutions with $5.000 \mu \mathrm{g} / \mathrm{mL}$ of amikacin, kanamycin, gentamicin and neomycin were prepared (Sigma Co., St. Louis, USA). The antifungal drugs solutions of $1024 \mu \mathrm{g} / \mathrm{mL}$ to amphotericin B were prepared (Sigma Co., St. Louis, USA), Mebendazole (Lasa - Pharmaceutical Industries LTDA., Brazil), Nystatin (Brazilian Laboratory Teuto S/A, Brazil), e Benzoilmetronidazole (Prati, Donaduzzi \& Cia LTDA., Brazil). The antibiotic solutions were prepared allowing the recommendations of NCCLS. ${ }^{6}$

\subsection{Preparation of ethyl acetate fraction (EAFPC) and hexane fraction (HFPC) from leaves of P. calomelanos (L.) Link}

Leaves of the plant (950 g) were dried and kept at room temperature. The powdered material was extracted by maceration using $1 \mathrm{~L}$ of $95 \%$ ethanol as solvent at room temperature. The homogenate was allowed to stand for $72 \mathrm{~h}$ at room temperature. The extract was filtered and concentrated under vacuum in a rotary evaporator (Q-344B - Quimis, Brazil) and ultrathermic bath (Q$214 \mathrm{M} 2$ - Quimis, Brazil) under $60{ }^{\circ} \mathrm{C}$ and $760 \mathrm{~mm} / \mathrm{Hg}$ of temperature and pressure, respectively. Each $500 \mathrm{~g}$ of aerial parts yielded $26.3 \mathrm{~g}$ of ethanol extract. Afterward, $20 \mathrm{~g}$ of ethanol extract was fractionated with hexane and ethyl acetate, producing $0.28 \mathrm{~g}$ and $9.25 \mathrm{~g}$ of material fractionated respectively. The fractions were diluted using DMSO.

\subsection{Phytochemical screening}

The phytochemical assays is to use for qualitative analysis of the presence secondary metabolites as: heterosides, saponins, tannins, flavonoids, steroids, triperpens, cumarins, quinones, organics acids and alkaloids were performed allowing the method described for Matos. ${ }^{7}$ The tests are analyzed by the color modification and by the formation of precipitate after of the addition of the reagents specifics. Table 2 presents the metabolites observes in hexane and ethyl acetate fractions.

\subsection{Minimum Inhibitory Concentration (MIC)}

The Minimum Inhibitory Concentration (MIC) was determined in $\mathrm{BHI} 10 \%$ by method of microtitration, using a suspension of $10^{5} \mathrm{UFC} / \mathrm{mL}$ and an initial drug concentration $1024 \mu \mathrm{g} / \mathrm{mL}$ for fungi and $5.000 \mu \mathrm{g} / \mathrm{mL}$ for bacteria. ${ }^{6}$ The MIC was defined as the lowest concentration at which no growth was observed. To the evaluation of the ethyl acetate fraction and hexane fraction as modulators of resistance to antibiotics and antifungal agents, a sub-inhibitory

Table 2

Phytochemical screening of hexane fraction (HFPC) and ethyl acetate fraction (EAFPC) from Pityrogramma calomelanos (L.) Link.

\begin{tabular}{|c|c|c|c|c|c|c|c|c|c|c|c|c|c|c|c|}
\hline \multicolumn{16}{|c|}{ Metabolites } \\
\hline & 1 & 2 & 3 & 4 & 5 & 6 & 7 & 8 & 9 & 10 & 11 & 12 & 13 & 14 & 15 \\
\hline HFPC & & & & & + & & + & + & + & & + & & + & & \\
\hline EAFPC & & & & + & & + & + & + & + & + & + & & + & & \\
\hline
\end{tabular}

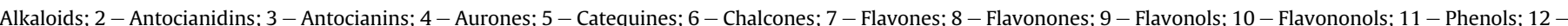

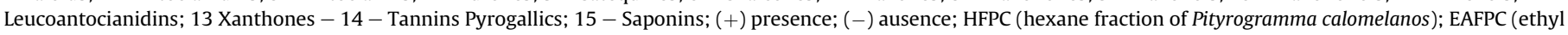
acetate fraction of Pityrogramma calomelanos). 
Table 3

Evaluation of modulator antifungals effect of hexane fraction (HFPC) and ethyl acetate fraction (EAFPC) of Pityrogramma calomelanos (L.) Link.

\begin{tabular}{|c|c|c|c|c|c|c|c|c|c|}
\hline & \multicolumn{3}{|c|}{ C. albicans } & \multicolumn{3}{|l|}{ C. krusei } & \multicolumn{3}{|c|}{ C. tropicalis } \\
\hline & ALONE & $+\mathrm{HF}$ & $+\mathrm{EAF}$ & ALONE & $+\mathrm{HF}$ & $+\mathrm{EAF}$ & ALONE & $+\mathrm{HF}$ & $+\mathrm{EAF}$ \\
\hline Anphotericin B & $\geq 1024$ & $\geq 1024$ & $\geq 1024$ & $\geq 1024$ & $\geq 1024$ & $\geq 1024$ & $\geq 1024$ & $\geq 1024$ & $\geq 1024$ \\
\hline Mebendazole & $\geq 1024$ & $\geq 1024$ & $\geq 1024$ & $\geq 1024$ & $\geq 1024$ & $\geq 1024$ & $\geq 1024$ & $\geq 1024$ & $\geq 1024$ \\
\hline Nystatin & $\geq 1024$ & $\geq 1024$ & $\geq 1024$ & $\geq 1024$ & $\geq 1024$ & $\geq 1024$ & $\geq 1024$ & $\geq 1024$ & $\geq 1024$ \\
\hline Benzoilmetronidazole & $\geq 1024$ & 128 & $\geq 1024$ & $\geq 1024$ & $\geq 1024$ & $\geq 1024$ & $\geq 1024$ & $\geq 1024$ & $\geq 1024$ \\
\hline
\end{tabular}

Hexane fraction of Pityrogramma calomelanos (HFPC); ethyl acetate fraction Pityrogramma calomelanos (EAFPC).

Table 4

Evaluation of modulator antibacterial effect of hexane fraction (HFPC) and ethyl acetate fraction (EAFPC) from Pityrogramma calomelanos (L.) Link.

\begin{tabular}{|c|c|c|c|c|c|c|c|c|c|}
\hline & \multicolumn{3}{|l|}{ E. coli } & \multicolumn{3}{|c|}{ S. aureus } & \multicolumn{3}{|c|}{ P. aeruginosa } \\
\hline & ALONE & $+\mathrm{HF}$ & $+\mathrm{EAF}$ & ALONE & $+\mathrm{HF}$ & $+\mathrm{EAF}$ & ALONE & $+\mathrm{HF}$ & $+\mathrm{EAF}$ \\
\hline Amikacin & 5000 & 9.765 & 9.765 & 78.125 & 78.125 & 625 & 1250 & 1250 & 1250 \\
\hline Kanamycin & 2500 & 312.5 & 2500 & 156.25 & 156.25 & 39.06 & 2500 & 2500 & 2500 \\
\hline Gentamicin & 625 & 625 & 625 & 312.5 & 4.88 & 4.88 & 1250 & 1250 & 1250 \\
\hline Neomycin & 156. 25 & 156.25 & 156.25 & 156.25 & 156.25 & 19.53 & 625 & 625 & 625 \\
\hline
\end{tabular}

Hexane fraction of Pityrogramma calomelanos (HFPC); ethyl acetate fraction Pityrogramma calomelanos (EAFPC).

concentration was used $(\mathrm{MIC} / 8=128 \mu \mathrm{g} / \mathrm{mL})$ and assayed using the follow strains: EC27, MRSA 358, C. albicans, C. krusei and C. tropicalis. The plates were incubated for $24 \mathrm{~h}$ at $37^{\circ} \mathrm{C}$.

\section{Results and discussion}

In the antimicrobial assays using the ethyl acetate fraction and hexane fraction, was determined the Minimum Inhibitory Concentration (MIC $\geq 1024 \mu \mathrm{g} / \mathrm{mL}$ ). To these fractions, there was not any clinically relevant antimicrobial activity against fungi or bacteria observed.

In the test of modulatory antimicrobial activity against multiresistant bacteria, was verified in $E$. coli that ethyl acetate fraction potentiated the effect of amikacin. The hexane fraction potentiated the effect of two antibiotics, amikacin and kanamycin. This result indicates the capacity of these fractions to facilitate the action of aminoglycosides on $E$. coli. In the assay with $S$. aureus, was observed that ethyl acetate fraction potentiated the antibiotic activity of kanamycin, gentamicin and neomycin. The hexane fraction potentiated the effect only in the gentamicin. For $P$. aeruginosa, no potentiation of antibacterial activity was observed. In the assay with fungi, any modulatory effect of the natural products over the antifungals against the species of Candida test was not observed, with exception of the Benzoilmetronidazole, that was potentiated against $C$. albicans when associated with the hexane fraction. These are the first reports about the antimicrobial and modifying antibiotic and antifungal activity of $P$. calomelanos (Tables 3 and 4).

There are several mechanisms by which the extracts may inhibit the growth of microorganisms and generally are associated with the hydrophobic nature of some components. These components could interact with the cell membrane, affecting the respiratory chain and the energy production, or even make the cell more permeable, leading to disruption of vital cellular activity and enhancing the antibiotic intake. Several compounds of extracts or fractions increase the permeability of the cell, raising the penetration of antibiotics. This effect can be obtained by the combination of antibiotics with extract or fractions in sub-inhibitory concentration applied directly to the culture medium. ${ }^{4,8}$

This strategy is called "herbal shotgun" and refers to the utilization of plants and drugs in an approach using mono- or multiextract combinations, affecting various targets. 9,10

\section{Conclusions}

This work revealed that natural products of $P$. calomelanos are effective antimicrobial-modifying agents. This information is promising and can incentive search futures about pharmacological aspects and toxicity of the natural products of $P$. calomelanos with the objective to promote the possible future use of natural products from this fern or from other plants in the antifungal and antibacterial therapy, as well as combat the problem of antibiotic resistance. Future works to identify the chemical compounds that are relevant from these activities are necessary, as well as other studies in vitro and in vivo before the possible combined use as new drugs.

\section{Conflicts of interest}

All authors have none to declare.

\section{Acknowledgments}

The authors are grateful to the Brazilian research agencies $\mathrm{CNPq}$ and FUNCAP, by the financial support.

\section{References}

1. Boyce JM. MARSA patients: proven methods to treat colonization and infection. J Hosp Infect. 2001;48:9-14.

2. Ferreira WA, Avila SLM. Diagnóstico Laboratorial das Principais Doenças Infecciosas; e Auto-Imunes. Rio de Janeiro: Guanabara Koogan; 2001.

3. Georgopapadakou NH. Infectious disease 2001: drug resistance, new drugs. Drug Resist Updat. 2005;5:181-191.

4. Piddock LJV. Clinically relevant chromosomally encoded multidrug resistance efflux pumps in bacterial. Clin Microbiol Rev. 2006;19:382-402.

5. Prado J. Flora da Reserva Ducke, Amazonas, Brasil: Pteridophyta - Pteridaceae Rodriguésia. 2005;56:85-92.

6. Clinical and Laboratory Standards Institute (CLSI). Reference Method for Broth Dilution Antifungal Susceptibility Testing of Yeasts. Approved Standard. 2nd ed. Atlanta: NIH; 2002. M27-A2.

7. Matos FJA. Introdução à química experimental. 3th ed. Fortaleza: Universidade Federal do Ceará; 2009.

8. Burt S. Essential oils: their antibacterial properties and potential applications in foods - a review. Int J Food Microbiol. 2004;94:223-253.

9. Coutinho HDM, Matias EFF, Santos KKA, et al. Enhancement of the norfloxacin antibiotic activity by gaseous contact with the essential oil of Croton zehntneri. J Young Pharm. 2010;2:4.

10. Coutinho HDM, Costa JGM, Lima EO, Falcão-Silva VS, Siqueira-Júnior JP Enhancement of the antibiotic activity against a multiresistant Escherichia coli by Mentha arvensis L. and chlorpromazine. Chemotherapy. 2008;54:328-330. 